\title{
EL TÍTULO POSESORIO EN EL DERECHO CIVIL PERUANO
}

\author{
Héctor Enrique Lama More*
}

\begin{abstract}
Resumen
El presente artículo se ocupa de la posesión en el marco del derecho civil peruano y centra su atención en la posesión y el rol del título en el ejercicio de este derecho real.

Se enfoca el derecho real de posesión desde el punto de vista del acto jurídico y el efecto de éste como causa del derecho posesorio, así como el derecho que le reconoce la ley al poseedor de un bien.

Título putativo y justo título, interversión del título de la posesión, la posesión mediata e inmediata, posesión legítima e ilegítima, la posesión precaria, son temas que se tratan en el presente artículo.
\end{abstract}

Palabras clave: Posesión, derecho real, acto jurídico.

\begin{abstract}
The present article is about the possession within the frame of the Peruvian civil right and focuses its attention on the possession and the roll of the title in the exercise of this real right.

The right of posesión is approached from the point of view of the legal act and its effect as a cause of the possessory right, as well as the right that the law recognizes to the possessor of the good.

Putative title and fair title, intervention of the title of the possession, the mediate and immediate possession, legitimate and illegal possession, the precarious posesión constitute subjects that are treated in the present article.

Keywords: Possession, real right, legal act.

\section{Sumario}

1. Introducción 2. Idea o concepto de título en la posesión. 3. Título putativo y justo título como títulos posesorios. 4. Interversión del título de la posesión. 5 . La posesión mediata, la posesión inmediata y el título posesorio. 6. Posesión ilegítima y el título posesorio. 7. Conclusiones.
\end{abstract}

* Vocal Titular de la Corte Superior de Justicia de Lima. Miembro del Consejo Consultivo del Centro de Investigaciones Judiciales del Poder Judicial. Profesor de la Universidad Nacional Mayor de San Marcos, Universidad de Lima y Academia de la Magistratura. 


\section{INTRODUCCIÓN. LA POSESIÓN, SU IMPORTANCIA}

Si tienes una manzana para consumirla, o tienes un vehículo -por ejemplo automóvil, bicicleta, etc.- y lo conduces desplazándote de un lugar a otro con fines laborales o de simple esparcimiento; cuando se accede a un inmueble para vivir en él o para instalar un negocio o realizar alguna actividad de tu interés o entregándolo a otro obtienes un provecho; o tienes un par de zapatos y con ellos en tus pies realizas tus cotidianas actividades; y en general cuando tomas cualquier bien o "cosa" respecto del cual tienes algún interés, y con él satisfaces alguna de tus necesidades -incluidas las más elementales o naturales, extrañas o inverosímiles, las más simples o complejas, las de orden material o espiritual, las de naturaleza científica o esotérica, etc.-, ejerces -de hecho- sobre dicho bien un poder que el sistema jurídico le reconoce al propietario; y sin interesar si eres o no el dueño de tales bienes, tal ejercicio desplegado fácticamente, expresa un derecho real que nuestro sistema jurídico reconoce como "posesión"; tal evento, que constituye señorío fáctico sobre bienes -aunque en algunos casos se presente como algo extraño o paradójicoes objeto de protección por el derecho. El ejercicio de éste derecho - posesoriotiene una clara connotación social y económica, y tiene obvia incidencia en la vida misma de las personas. De ahí la importancia de su estudio y la de su correcta regulación por el derecho.

La posesión, como se puede apreciar, se encuentra presente en la mayoría de actividades que de modo cotidiano realizan las personas en general.

Diversos autores han comentado sobre la importancia de la posesión; así, desde argentina, Ricardo José Papaño y otros ${ }^{1}$, señalan que la posesión es el contenido de los derechos reales, pues en la mayoría de éstos sin ella no sería posible el ejercicio de las facultades que otorgan a sus titulares.

La posesión hace realidad el derecho de propiedad; la propiedad sin posesión es propiedad vacía, sin contenido, es sólo abstracción, es simplemente un "derecho", no es realidad; tal situación respecto de la posesión resulta perfectamente aplicable a cualquier otro derecho real -sea a los de goce, como a los de realización de valor o de garantía-. Lo particular de la posesión es que también puede presentarse sola, es decir, de modo independiente de cualquier otro derecho real.

En esto corresponde distinguir, como bien lo hace $\mathrm{Messineo}^{2}$, entre el derecho a la posesión, que cierta terminología muy antigua la identifica como ius possidendi, que se presenta como la potestad de tener la posesión, -pudiendo o no corresponder en acto la posesión efectiva- pero que de todos modos se 
funda en un título, del derecho de posesión (ius possessionis), considerada en si misma, en cuanto ejercicio efectivo, independientemente de la circunstancia de que, como base de la posesión, esté un fundamento o título, y que -según indica el citado autor- puede corresponder a quienquiera.

Efectivamente, la posesión puede presentarse como consecuencia del ejercicio de un derecho de propiedad o de otro derecho real o personal o en virtud de un derecho conferido por la ley (ius possidendi); o puede aparecer -en su ejercicio- sin más, en sí, es decir sin considerar que exista o sea consecuencia de otros derechos reales (ius possessionis). En este último supuesto, como lo refiere Hernandez $\mathrm{Gil}^{3}$, se evidencia su autonomía; no obstante, se nos presenta como una figura compleja; debido a las diversas ideas que sobre ella se han expuesto en la doctrina ${ }^{4}$, las que, como se sabe, expresan conceptos distintos acerca de la posesión; apareciendo en paralelo -y muchas veces como referencia- una figura muy cercana pero de naturaleza distinta: la tenencia.

Se trata, en realidad, del ejercicio de un poder sobre bienes que para ser considerada como tal, es decir como posesión en el sentido estricto, se requiere de cierta cualidad, la que debe tenerse en cuenta para distinguirla de otras figuras, algunas de las cuales son reconocidas por el derecho. Por ello se debe tener presente que, salvo que la ley regule lo contrario, la posesión debe ser considerada como la potestad o señorío fáctico que, con interés propio, ejerce una persona sobre un bien para su aprovechamiento económico y la satisfacción de sus necesidades; debiendo considerarse poseedor aquel que, aún cuando reconozca en otro la propiedad, en los hechos obra o se conduce como propietario usando o disfrutando el bien ${ }^{5}$.

El concepto antes referido -compatible con nuestro sistema jurídico- permite una rápida diferenciación del que le corresponde a la tenencia. Pues si la persona tiene el bien en su poder pero en interés ajeno, es decir, por encargo o siguiendo instrucciones de otro, estaremos frente a la tenencia. La doctrina la identifica como servidor de la posesión ${ }^{6}$; algunos autores la identifican como tenencia relativa, en razón de que se tiene el bien, no obstante no se posee por la relación de dependencia -o de autoridad y subordinación-, que tiene con determinada persona, que es precisamente el poseedor; es el caso de la relación generada por el arma entregada al soldado, el inmueble entregado al guardián, el negocio entregado al administrador, etc;

Sin embargo existen otros supuestos de tenencia distintos al servidor de la posesión, como es el caso de aquellos que tienen el mero contacto con los bienes o que obran en su poder por razones de naturaleza accidental o pasajera, a los que se les conoce como tenencia absoluta, en razón de que tienen contacto 
físico sobre los bienes sin que los haya recibido en virtud de una relación de subordinación con persona alguna; es el caso de los grilletes que tiene el preso, o la butaca que se tiene en el teatro o cine; el campus universitario cuando el alumno camina en él; o la revista que le fue prestada al pasajero por su compañero de viaje para ser leída y devuelta de inmediato; etc.

Siendo que tenedor y poseedor se presentan ante terceros como personas que tienen en su poder bienes, resulta necesaria una idónea regulación de ambas instituciones jurídicas. En la tenencia quien tiene el bien pero no lo posee. En la posesión se tiene el bien en virtud de un título o sin título alguno.

En esta oportunidad centraremos nuestra atención en la posesión y el rol del título en el ejercicio de este derecho real.

Una apreciación rápida de nuestro Código Civil en materia referida al derecho posesorio permite una inmediata, sencilla e importante conclusión: no existe un adecuado e idóneo tratamiento normativo sobre el título en la posesión de bienes; ello pese a la relevante incidencia que este elemento tiene en la calificación sobre la licitud, validez o legitimidad del señorío fáctico sobre bienes o del ejercicio que -de hecho- llevan adelante las personas de los poderes jurídicos que el sistema reconoce al propietario.

\section{IDEA O CONCEPTO DEL TÍTULO EN LA POSESIÓN.}

\subsection{TÍTULO POSESORIO COMO ACTO JURÍDICO.}

Diversos autores, nacionales como extranjeros, han señalado que el título, en torno al cual gira la posesión, no es necesariamente un documento, sino el acto jurídico que dio origen a la posesión; con ello se incide, predominantemente, en la autonomía de la voluntad; concentrando la atención en el título posesorio adquirido bajo la forma derivativa, es decir obtenido de otra persona; así, por ejemplo, el profesor sanmarquino Max Arias-Schreiber ${ }^{7}$, al comentar sobre la necesaria existencia del título como uno de los elementos de la posesión ilegítima de buena fe, refiere que éste no es otra cosa que el acto jurídico por el cual se transmite la posesión de un bien, ya sea en propiedad, usufructo, arrendamiento o comodato, entre otros; aún cuando al final establece, de modo genérico, que el título viene a ser la causa generadora del derecho, en estricto su atención se encuentra centrada en la manifestación de la voluntad.

Salvat ${ }^{\varepsilon}$ nos refiere que la palabra título se emplea en derecho para designar, sea al acto jurídico que ha dado nacimiento al derecho, la causa de él, sea el 
documento que lo constata y sirve de prueba de su existencia; pero aclara que cuando se refiere a la posesión ilegítima -regulada en el artículo $2355^{\circ}$ del Código Civil de su país- la palabra título está empleada en el primero de los dos sentidos indicados, es decir, el que lo considera como acto jurídico, que constituye la causa de su derecho.

En nuestro país, el profesor Jorge Avendaño ${ }^{9}$ sigue, en esto, la idea expuesta por el citado jurista argentino -Raymundo Salvat- al precisar que la palabra título -en la posesión ilegítima- está empleada en términos del acto jurídico que ha dado nacimiento al derecho, es decir, la causa de la posesión; el profesor Avendaño insiste es esta calificación al precisar que la posesión será ilegítima cuando falta el título, cuando hay ausencia del acto jurídico que da lugar a la posesión legítima. No obstante, el citado jurista peruano, al igual que Salvat, aclara que puede ocurrir que el título siendo perfectamente válido haya sido otorgado por quien carezca de derecho; es el caso de un contrato de arrendamiento extendido por un no propietario; concluye señalando que a pesar de la existencia de un título válido, el arrendatario sería un poseedor ilegítimo, pues estaría derivando su derecho de una persona carente de facultad para otorgarlo.

\subsection{TÍTULO COMO CAUSA DEL DERECHO POSESORIO}

Si bien es correcto afirmar que el título de la posesión puede estar referido al acto jurídico que constituye la causa del derecho posesorio, como lo han expuesto los autores antes citados; es también válido afirmar que ello es sólo una de las expresiones que puede tener el título posesorio; debemos entender, como así lo ha hecho nuestra jurisprudencia, que el título que da sustento a la posesión y que la justifica jurídicamente, puede estar referido no a la manifestación de voluntad de determinada persona -acto jurídico-, sino a fuente distinta, como la ley o un hecho o acontecimiento jurídico que de modo válido justifica prima facie - en algunos casos de modo temporal- el ejercicio del derecho posesorio de una persona.

Previamente, es preciso establecer que en la idea que se tiene sobre la posesión de bienes muchas veces se prescinde de la existencia del título; así, como bien lo precisa Messineo ${ }^{10}$, aún sin título, la posesión tiene relevancia para el derecho; pero, agrega algo muy importante, no se excluye tampoco que además del hecho de la posesión, exista un título como fundamento de la posesión misma; en tal caso la posesión es manifestación derivada de otro poder; así, concluye, que la posesión, con título, frente a un eventual juicio petitorio se encuentra en una situación mejor que el poseedor sin título. 
Como se puede apreciar, para este autor, el título es la causa que da justificación jurídica a la posesión; no obstante, aclara, que si el título de la posesión deriva del título del derecho subjetivo, no forma un todo único con él, pues si se posee por ser arrendatario o inquilino, el título de la posesión está en el arrendamiento o en el alquiler; cosa distinta es que sea arrendatario o inquilino; pues tal posibilidad puede existir, aún sin que se tenga la posesión, o sea, antes de comenzar a poseer.

En nuestro país Toribio Pacheco ${ }^{11}$, comentando el Código Civil Peruano de 1852, refiriéndose a la posesión -con título o sin título-, señaló con singular precisión que en materia posesoria, se entiende por título un hecho capaz de producir efectos civiles, o la causa de un derecho verdadero o aparente. Aludiendo a la posesión como base de la prescripción, señala que será título el hecho que ha dado origen a la posesión, es decir la causa de ésta.

Esta definición se presenta de manera más amplia y permite un espectro mayor en el estudio y tratamiento del título posesorio, superando el estrecho marco que impone la autonomía de la voluntad -acto jurídico-.

En esta misma línea se enmarca la definición hecha por el jurista Julio Verdugo, en su obra "Del título en la posesión" -citado por el profesor chileno Victorio Pescio $^{12}$, quien al referirse a las diversas significaciones asignadas por el derecho al vocablo "titulo", centrándose a la posesión sostiene que es la causa jurídica de la posesión, esto es, aquel hecho o conjunto de hechos de los cuales se deriva la posesión como una consecuencia jurídica.

\subsection{TÍTULO POSESORIO CONCEBIDO COMO EL DERECHO QUE LA LEY RECONOCE AL POSEEDOR}

El derecho que la ley reconoce al poseedor, respecto de un bien determinado, puede constituir la causa del derecho a la posesión del citado bien. Así ha quedado establecido en reiterada jurisprudencia nacional, veamos.

Hace unos meses tuve la oportunidad de tener a la vista los actuados judiciales de un proceso de desalojo, en el que consta la Casación $N^{\circ}$ 3135-99 - Lima, de fecha 13 de Junio del año 2000, expedida por la Sala Civil Permanente de la Corte Suprema de la República ${ }^{13}$. Se trata de un proceso iniciado por ante el vigésimo Juzgado Civil de Lima donde el demandante pretende la restitución de un inmueble de su propiedad, indicando como fundamento que éste se encuentra ocupado por la demandada con quien no le une vínculo contractual, que no cuenta con título alguno y que por ello tiene la condición de precaria; en autos se acredita que la demandada residía en dicho inmueble con su me- 
nor hijo tenido con el demandante fruto de relaciones de convivencia; el Juzgado ampara la demanda -teniendo en cuenta el estado procesal de rebeldía de la demandada- y dispone la restitución del bien; apelada la sentencia la Sala Superior la confirma, con el argumento que el menor hijo de la demandada viene percibiendo del demandante una asignación anticipada de alimentos y que en ella se incluye lo indispensable para el sustento, habitación, vestido y asistencia médica. Interpuesto el recurso de casación la Sala Civil Suprema declara fundado dicho recurso, casa la sentencia de vista, y -actuando en sede de instancia- revoca la sentencia del juzgado y reformándola declara infundada la demanda; en dicha ejecutoria se establece que "la posesión ejercida por el hijo menor de edad sobre los bienes de propiedad del padre, nunca va a ser una posesión precaria, pues su título posesorio es justamente su calidad de hijo" (resaltado nuestro); agrega el colegiado supremo que "el solo hecho de acudir a los hijos con una pensión alimenticia, no exime al padre de la obligación de proporcionarles vivienda, pues este hecho, debe ser tomado en cuenta a efectos de fijar la pensión, y no tiene efecto alguno en la calidad posesoria del hijo"; finaliza precisando que de obtenerse el desalojo de la madre, que ejerce la tenencia del menor, se estaría obteniendo de forma indirecta el desalojo del hijo, quien no tiene la calidad de precario.

Haciendo abstracción de los asuntos procesales -rebeldía de la demandada, situación procesal del menor, etc.-se pueden extraer del citado pronunciamiento supremo algunas conclusiones en materia sustantiva, referidas al título posesorio y su validez:

a. El título posesorio que es la causa o fundamento de la posesión es el derecho que la ley reconoce al poseedor. En tal supuesto el título no es un acto jurídico.

b. En el presente caso, la ley impone al padre la obligación de proporcionar habitación o vivienda a sus menores hijos -dentro del concepto de alimentos-; tal derecho del menor es el título posesorio respecto del bien, de propiedad del padre, donde reside.

c. La madre que ejerce la tenencia del menor, cuenta también con título posesorio, en la medida que ejerza la tenencia de su menor hijo y resida con él en el mismo inmueble. A diferencia del menor, su títul o posesorio no es el derecho a vivienda -como sucede en el caso del menor- es, en estricto, un derecho distinto, es el que emana de su condición de madre y de la propia tenencia que ejerce respecto del menor, el que a su vez concurre con el derecho del menor de no ser separado de quien le provee los cuidados, en este caso, su progenitora. 
Tiene título posesorio justificativo quien construyó edificación en terreno ajeno, en tanto no se decida en sede judicial el destino de la edificación bajo las reglas de la accesión. La Casación $N^{0} 1763$-Lambayeque ${ }^{14}$, estableció que no tiene la condición de precario -según el artículo $911^{\circ}$ del Código Civil, es poseedor precario quien posee un bien sin título alguno- quien es dueño de la edificación construida sobre el terreno de la demandante.

En este caso el título de posesión de la demandada consiste en el derecho que la ley reconoce a quien construye un bien -aún en terreno ajeno- en tanto no se dilucide -en sede judicial- si la construcción se levantó de buena o mala fe.

\section{TÍTULO PUTATIVOYJUSTO TÍTULO,COMOTÍTULOS POSESORIOS}

El título putativo y el justo título, adquiridos de buena fe por el poseedor, aún cuando constituyen una variedad de posesión ilegítima, constituyen títulos posesorios que pueden justificar válidamente la posesión de bienes, en tanto, según las circunstancias, no se desvirtúe por completo la buena fe, o en su caso no se declaren -por el órgano jurisdiccional- su invalidez o ineficacia.

Se considera título putativo al título inválido obtenido de buena fe.

Salvat ${ }^{15}$, comentando el artículo $2357^{\circ}$ del Código Civil de su país, refiere que en el derecho argentino el título putativo es aquel que solo existe en la creencia del poseedor, y que puede presentarse en dos supuestos: 1) cuando el título falta de modo absoluto; y 2) cuando el título existe pero no se aplica a la cosa poseída; para explicar el primer supuesto, se refiere el caso del legatario que ha entrado en posesión de la cosa legada, ignorando que el testamento había sido revocado; y si después aparece un nuevo testamento donde consta que la cosa ha sido legada a otro, que la reivindica, resulta necesario saber si existía o no buena fe; agrega el jurista argentino que para resolver esta cuestión se debe tener en cuenta si existía o no justo título y la ley resuelve que cuando el título existía solo en apariencia o para emplear la fórmula legal, en la creencia del poseedor, el título es eficaz; con relación al segundo supuesto se expone el caso de una apersona que entra en posesión de los bienes que, según él, son de la herencia, pero que luego toma conocimiento que no era así.

Es necesario, sin embargo, distinguir entre título putativo y justo título.

En principio diremos que el primero de ellos es insuficiente para adquirir bienes por la prescripción ordinaria, así lo reconoce Salvat ${ }^{16}$ en el derecho argentino, y el maestro sanmarquino Jorge Eugenio Castañed $a^{17}$ en nuestro país; éste último refiere que si bien el título putativo no sirve para la usucapión, 
dicho título no transforma al poseedor en poseedor de mala fe, ya que para la posesión de buena fe -aunque ilegítima- solo se requiere título, "aún cuando éste sea rematadamente malo" (sic).

Un caso típico de título putativo, expone el citado jurista nacional, es el que se da si A otorga poder a B para que le compre un inmueble determinado; en efecto, $B$ afirma haberlo comprado y pone en posesión de dicho inmueble a su mandante A; es obvio que la posesión de A no se sustenta en un justo título -sino en un título putativo-, si realmente B no compró el bien y no comunicó de tal hecho a su mandante.

Por otro lado, la posesión puede estar sustentada en el denominado justo título. A diferencia del título putativo, el justo título que es en esencia un acto traslativo de dominio -adquirido de buena fe de quien no es propietariopermite al poseedor adquirir por prescripción corta $-\mathrm{u}$ ordinaria- el bien que tiene en su poder. Aún cuando nuestro Código Civil no ha establecido las características que debe tener tal título posesorio, la doctrina, nacional y la que se expone en el derecho comparado, es uniforme al considerar que se trata de un título suficiente para adquirir el dominio del bien que se posee, según los modos o formas prescritos en la ley; así, por ejemplo si una apersona recibe en posesión un bien en virtud de una compra venta, pensando que quien le vendió era el propietario y en realidad no lo era, ni se encontraba autorizado para enajenar el bien; o cuando se posee en virtud a una donación hecha a favor del poseedor, cumpliendo las formalidades establecidas en la ley para tal acto jurídico -por escritura pública si se trata de inmueble-, pero el donante no se encontraba habilitado para efectuar tal transferencia.

El justo título -para el profesor Castañeda ${ }^{18}$ - no es el instrumento sino el negocio jurídico que sirve de causa a la transferencia del dominio; sin embargo, como ese negocio jurídico deberá acreditarse, la prueba más sólida es la instrumental. Debe tenerse en cuenta que en este caso quien transfiere no es el propietario, pues, obviamente, si lo fuera la transferencia se hubiera producido y estaríamos frente a la posesión del nuevo propietario, y no se requeriría de la usucapión para adquirir la propiedad del bien.

En el derecho civil español se considera justo título como el que legalmente baste para transferir el dominio o derecho real de cuya prescripción se trate; Albaladejo ${ }^{19}$ refiere que ello significa acto transmisivo, como compraventa, donación, transacción, permuta etc., apto para -en abstracto- haber producido la adquisición del derecho -de propiedad u otro- de que se trate, y que en el caso concreto no la produjo, por cualquier razón externa a él -como por 
ejemplo que la cosa que compramos, se nos donó o concedió en transacción no era del vendedor o donante o transigente-.

Históricamente se han identificado diversos títulos posesorios que han pretendido ser considerados como "justo título" para justificar la adquisición de la propiedad por usucapión; así tenemos el título de heredero conocido como título pro haerede; se trata del título posesorio que tendría quien creyéndose heredero accede a la posesión de bienes de la herencia, cuando en realidad no tiene tal condición; o quien siendo heredero accede a la posesión de bienes creyendo que son de la herencia, cuando en realidad no lo son; es evidente, como lo reconocen Albaladejo ${ }^{20}$ y Castañeda ${ }^{21}$, que ambos supuestos de títulos pro haerede no son justo título en razón de que no constituyen actos traslativos de dominio y no son suficientes para adquirir los bienes objeto de posesión por prescripción ordinaria -o corta-.

En términos generales, el justo título debe ser trasmisivo o traslativo, no debe ser originario; así por ejemplo no constituye justo título el que se tiene por poseer cosa abandonada, conocida en la doctrina como título pro derelicto. Si el bien abandonado es mueble, se trataría de una res nullius es decir una cosa sin dueño; podrá adquirirse la propiedad por apropiación; si el bien abandonado es inmueble será siempre del Estado.

Tampoco es justo título el título pro legato ${ }^{22}$; se trata del título que tiene quien como legatario recibe un bien que no era propiedad del causante pero que éste estaba usucapiendo en virtud de cualquier título; aquel continuará como sucesor de la usucapión basada en dicho título.

El título putativo y el justo título -adquiridos de buena fe por el poseedorson títulos posesorios que expresan una variedad de posesión ilegítima de buena fe; no obstante, dejarán de ser títulos justificativos de la posesión en la medida que desaparezca la buena fe; en tal caso, estaremos frente a un poseedor ilegítimo de mala fe y su situación jurídica es la que equivale a la de posesión sin título.

\section{INTERVERSIÓN DEL TÍTULO DE LA POSESIÓN}

Una antigua regla de origen romano establecía que: nadie puede cambiar por si mismo, ni por el transcurso del tiempo, la causa de su posesión.

Si la posesión que se ejerce deviene en tenencia o la tenencia deviene en posesión, se dice que se ha producido la interversión o mutación del título posesorio. Sin embargo, es necesario precisar que el concepto de posesión y 
el de tenencia; variará teniendo en cuenta la teoría posesoria a la que se ha adscrito el sistema jurídico vigente en cada país.

La figura de la interversión del título de posesión es aplicable tanto a los sistemas jurídicos que se adscriben a la teoría subjetiva de la posesión -impulsada por Savigny- como a aquellos que se han adherido a la teoría objetiva de la posesión, sostenida por Ihering y otros juristas; en los primeros se consideran poseedores a aquellos que cuentan con "animus domini", es decir a quienes tienen el bien sin reconocer en otro la propiedad, y tenedores a aquellos que tienen el bien en "interés ajeno", es decir reconociendo en otro la propiedad, ubicándose en éste último el arrendatario, el comodatario, el usufructuario, el precario clásico, etc; en los sistemas que se adscriben a la segunda de las citadas teorías -entre los que se ubican el peruano, brasilero y mexicano- se identifica al poseedor a aquel que tiene el bien ejerciendo sobre él un señorío fáctico o un poder de hecho similar a la que se le reconoce al propietario, pero en interés propio, entendido éste como aquel que satisface su propia necesidad, aún cuando se reconozca en otro la propiedad del bien que se tiene en su poder, en este sistema es poseedor el arrendatario, el comodatario, el usufructuario, el precario - tanto el que se conoce en el sentido clásico, como el que se identifica en el artículo $911^{\circ}$ del actual Código Civil. Peruano-; identificándose como tenedor a aquel que tiene el bien por encargo o siguiendo instrucciones de otro; se ubican en este grupo, por ejemplo al guardián, al depositario, etc.

Pues bien, en materia de interversión del título posesorio, Pescio ${ }^{23}$, que sigue al sistema savigniano de la posesión, vigente en el derecho civil chileno de Andrés Bello, sostiene que en los dos tipos de interversión -la transformación del poseedor en mero detentador o a la inversa, transformación del mero detentador en poseedor- subsiste inalterable el elemento físico o material de la posesión, es decir la tenencia de la cosa; lo que varía -según refiere- es el elemento psíquico o intelectual; así en transformación de poseedor en tenedor, el bien sigue en poder del que poseía pero a partir de un momento dado la retiene reconociendo en otro el dominio; en el segundo tipo de interversión el mero detentador que tiene la cosa nomine alieno, es decir, reconociendo el dominio ajeno, cambia de disposición de ánimo y, en lo sucesivo la retiene con ánimo de señor: el nomine alieno a sido sustituido por el animus domini.

Ihering, citado por Salvat ${ }^{24}$, refiere que la célebre regla de origen romano -mencionada líneas arriba- no puede considerarse aplicable solamente a los casos de transformación de una tenencia en posesión o viceversa, como parecería denominarlo la palabra Mutare de la máxima romana, sino que debe aplicarse también al hecho mismo del nacimiento de la relación posesoria; así 
ella nacerá como simple tenencia o como posesión, según sea la causa que la origina con prescindencia absoluta de la voluntad individual del adquiriente, impotente para modificar por si sola los efectos de aquella.

Castañeda $^{25}$, bajo la vigencia del Código Civil Peruano de 1936 -adscrito a la teoría objetiva de la posesión-, señala que la interversión del título no se produce por el simple cambio en la voluntad del poseedor inmediato, sino por causa que provenga de un tercero o por la contradicción que oponga al derecho del propietario. Diversos tratadistas -entre ellos Butera- agregan que si no se prueba el cambio de la causa o de título se presumirá que continúa la mera tenencia, porque es perpetua e indeleble.

En nuestro sistema jurídico vigente, la interversión del título de la posesión puede presentarse de diferente manera; así por ejemplo: el arrendatario puede mutar su título si adquiere la propiedad del bien que posee; el guardián dejará de ser tenedor o servidor de la posesión si intervierte su título al empezar a pagar renta, convirtiéndose en arrendatario, y como tal en poseedor; si el arrendatario deja de pagar renta por efecto de la conclusión del arrendamiento, su título posesorio muta y se convierte en un poseedor precario -según el artículo $911^{\circ}$ del actual Código Civil Peruano-, y como tal, apto para adquirir el bien que posee por prescripción si cumple con los requisitos que prevé el artículo $950^{\circ}$ del actual Código Civil. Peruano; si el guardián deja de seguir instrucciones del poseedor y ante el requerimiento de éste, se resiste a la entrega del bien, haciendo uso de él en interés propio y por su cuenta, deja de ser detentador y se convierte en poseedor sin título alguno -precario-; así, también habrá intervención del título si el que posee el bien de su propiedad lo vende y continúa en uso del mismo, pues habrá mutado su título posesorio, al pasar de poseedor como propietario, al de simple poseedor, salvo que se mantenga en posesión del bien con anuencia del comprador, o resistiéndose a la entrega -sin título-, en cualquier caso su status posesorio habría disminuido, etc.

En todos los casos citados en el párrafo precedente, para que se considere producida la interversión del título debe tenerse en cuenta, como lo señala Musto ${ }^{26}$, que no bastan las simples manifestaciones de la voluntad, sino que la actitud debe consistir en hechos exteriores que impliquen una verdadera contradicción a los derechos del propietario, un verdadero alzamiento contra su derecho, $o$ actos de fuerza que impidan al propietario el ejercicio de su derecho.

Diversas legislaciones han regulado, aunque parcialmente la figura materia de comentario; así en el Código Civil Brasilero se identifica el precepto que establece: “Salvo prueba en contrario, se entiende que la posesión se mantiene con el mismo carácter con que fue adquirida". Esta presunción sigue la lógica 
de la regla romana citada al empezar este punto. En el derecho argentino se conoce el precepto contenido en el Código Civil que establece: "Nadie puede cambiar por sí mismo, ni por el transcurso del tiempo, la causa de su posesión. El que comenzó a poseer por si y como propietario de la cosa, continúa poseyendo como tal, mientras no se pruebe que ha comenzado a poseer por otro. El que ha empezado a poseer por otro, se presume que continúa poseyendo por el mismo título, mientras no se pruebe lo contrario".

No existe en nuestro país una regulación idónea sobre esta materia; en realidad no se ha legislado nada relacionado a los alcances jurídicos de la mutación del título posesorio, pese a la gran importancia que reviste esta figura.

\subsection{LA TRADITIO BREVI MANU, EL CONSTITUTO POSESORIO Y LOS EFECTOS DEL CAMBIO DEL TÍTULO POSESORIO}

Lo único que existe regulado en el actual Código Civil peruano, con relación al cambio del título posesorio se encuentra ubicado normativamente en los llamados sucedáneos de la tradición, previstos en el artículo $902^{\circ 27}$. Se trata de supuestos donde la relación posesoria cambia, produciéndose una mutación del título de la posesión, cuyo efecto inmediato es el haberse producido o no la tradición o entrega del bien a quien debe recibirlo. Se trata de las figuras de origen romano conocidas como la traditio brevi manu y el constituto posesorio, las que, como es obvio se encuentran vinculadas a los efectos de la interversión -o transformación- del título posesorio.

Comentando acerca de la transformación de la relación posesoria, Valencia $Z_{e}{ }^{28}$ señala que no solo es necesario sentar la presunción relativa de continuidad de la posesión inicial; es preciso agregar cómo puede destruirse dicha presunción, es decir en qué casos una posesión se transforma en otra: Refiere -siguiendo la lógica de la teoría subjetiva de la posesión- que el constituto posesorio tiene la virtualidad de transformar una posesión en nombre propio en una posesión en nombre ajeno; y la traditio brevi manu implica la transformación de una posesión en nombre ajeno en una posesión de propietario, como cuando el arrendatario compra la cosa al dueño.

Aplicadas las mismas figuras -de origen romano- a nuestro país, que sigue las reglas de la teoría objetiva de la posesión, tendremos que el supuesto conocido como traditio brevi manu, se presenta cuando, por ejemplo, quien posee un bien en virtud de un arrendamiento -título posesorio de arrendatarioadquiere la propiedad de dicho bien; en este caso el título posesorio muta del de arrendatario al de propietario; como adquiriente tiene derecho a que se le entregue el bien, sin embargo se entiende entregado en bien al poseedor 
-ahora propietario- por haber cambiado su título posesorio, lo que se logrará reteniendo el bien que ya se encontraba en su poder. Hay también traditio brevi manu, cuando el guardián -tenedor no poseedor- empieza a pagar renta, convirtiéndose por ello en poseedor arrendatario; y teniendo derecho a recibir el bien, se entiende entregado por haber mutado el título posesorio, lo que sucederá reteniendo el bien en su poder.

En el constituto posesorio la mutación del título se presenta en descenso; así por ejemplo si alguien que posee un bien de su propiedad y lo transfiere, y acto seguido celebra con el adquiriente un arrendamiento, de tal manera que continúa en uso del bien vendido, sigue siendo poseedor, no obstante el título posesorio se transformó produciéndose una disminución de la calidad del mismo, pues ahora posee el bien ya no como propietario, sino como un simple arrendatario. Por otro lado, es aplicable también a esta figura -constituto posesorio- la tradición originada en la mutación de la relación posesoria que existía entre la persona que poseía el bien como arrendatario y el propietario arrendador, producida cuando aquel deja de pagar la renta y conviene con el propietario en dar el servicio de guardianía del bien que ocupa, recibiendo por tal servicio una contraprestación económica; en este supuesto quien tenía el bien como poseedor, lo tendrá en adelante como detentador; puede, en este caso, objetarse el hecho de que en este supuesto el detentador no tiene título posesorio y que por ello no se habría producido mutación del título sino su desaparición; sin embargo, para los fines materia de este estudio, tal objeción resultaría irrelevante, pues, lo que importa en esta figura es el hecho que el bien continuó en poder de quien era poseedor no requiriéndose actos materiales adicionales para la entrega del mismo; y además tal situación se produjo como consecuencia de una disminución de la calidad del poder que ejercía sobre el bien, que es lo que caracteriza al constituto posesorio.

Las figuras antes referidas se encuadran dentro de los alcances del inciso 1) del artículo $902^{\circ}$ del actual Código Civil, referidos a los sucedáneos de la tradición; los ejemplos consignados en los párrafos precedentes son solo una parte de lo que puede suceder en esta materia. A continuación analizaremos otros supuestos.

\section{LA POSESIÓN MEDIATA, LA POSESIÓN IN MEDIATA Y EL TÍTULO POSESORIO}

Nuestro sistema admite la posibilidad de la posesión aún sin el contacto físico con el bien; la doctrina la reconoce como una posesión como derecho o espiritualizada; se trata de un poseedor que no tiene físicamente el bien, pero 
que, pese a ello ejerce uno de los atributos de la propiedad; es el caso, por ejemplo del poseedor mediato que entregó el bien a otra persona -poseedor inmediato- en virtud a un título ${ }^{29}$. Hernandez $\mathrm{Gil}^{30}$ refiere que se trata de un fenómeno conocido como la "concurrencia horizontal de posesiones". Intentando una definición, el citado autor refiere que posesión mediata es la que se ostenta o tiene a través de otra posesión, correspondiente a persona distinta con la que el poseedor mediato mantiene una relación, de donde surge la dualidad posesoria.

En el derecho alemán al "poseedor mediato" se le conoce como poseedor superior y al "poseedor inmediato" como mediador posesorio o sub poseedor; Enneccerus ${ }^{31}$ precisa que la "posesión mediata" es la que se tiene por mediación de la posesión de otro; entre el "poseedor mediato" y la cosa media aquel que -en contraposición al servidor de la posesión- tiene la posesión misma. Por otro lado, refiere el mencionado jurista la "posesión mediata" es susceptible de varios grados, por ejemplo se considerarán series de la posesión: arrendador, sub arrendad or; sub arrendatario; en este caso habrán dos poseedores mediatos y un poseedor inmediato, ello en razón de que -como lo refiere Albaladejo- la posesión mediata siempre es una posesión de derecho, nunca de hecho. La doctrina reconoce una serie mayor de grados.

Es del caso precisar que la relación entre el poseedor mediato y el poseedor inmediato no tiene que ser válida; Arias-Schreiber ${ }^{32}$ señala que así ha quedado claramente establecido en la doctrina germánica; efectivamente Enneccerus $^{33}$ sostiene que el poseedor mediato es únicamente el que tenga una pretensión válida de entrega. No hace falta -agrega- que dicha pretensión sea incondicional ni que esté exenta de excepciones; ni tampoco necesaria, finalmente, la validez de la relación de arrendamiento, usufructo, porque la ley no presupone que el mediador sea arrendatario, usufructuario, sino sólo que posea como arrendatario o como usufructuario.

Como se sabe, este fenómeno posesorio fue incorporado a nuestro sistema de derechos reales en el Código Civil de 1936; el artículo $825^{\circ}$ de dicha norma señaló: "El poseedor temporal, en virtud a un derecho es poseedor inmediato, correspondiendo la posesión mediata a quien le confirió el derecho". Tal definición de la mediación posesoria se prestaba a confusión, pues podría pensarse que la relación jurídica existente entre ambos poseedores -mediato e inmediato- tendría que ser, necesariamente, arreglada a derecho; es decir una relación válida; cuando la doctrina más autorizada sobre esta materia reconoce que dicha relación podría no ser válida, como se ha indicado líneas arriba; por ello con la entrada en vigencia del actual Código Civil Peruano -vigente 
desde 1984- se reemplazó la palabra "derecho" por la de "título"; en realidad no se trata de un problema semántico, sino de una precisión normativa en la cualidad de la posesión.

\subsection{MEDIACIÓN POSESORIA EN LOS SUCEDÁNEOS DE LA TRADICIÓN}

La concurrencia posesoria tiene presencia también en los sucedáneos de la tradición, prevista en el artículo $902^{\circ}$ del actual Código Civil. Así tenemos que en el supuesto previsto en el segundo inciso de dicha norma sustantiva, en el sentido que la tradición se considera realizada si se transfiere el bien que está en poder de un tercero, en cuyo caso, precisa la norma, la transmisión produce efecto, respecto del tercero, sólo desde que le es comunicada por escrito. Se trata de la entrega tácita al tercero que se produce respecto del nuevo dueño o el adquiriente; es decir que el bien transferido se entiende entregado al tercero poseedor por el nuevo dueño desde que se le comunica -por escrito- de la transferencia. El tercero sigue siendo poseedor inmediato, pero ahora del nuevo dueño.

Cosa distinta sucede con los que integran la relación jurídica de la transferencia, es decir entre el transferente y el adquiriente del bien -ocupado por un tercero-; en este caso se presenta el desplazamiento de la mediación posesoria, de tal manera que el original poseedor mediato traslada su condición al adquiriente quien en adelante será el nuevo poseedor mediato, quien adquiere además -con la transferencia- la pretensión de entrega que podrá dirigirla al tercero -mediador posesorio-. Este desplazamiento posesorio espiritualizado produce sus efectos entre las partes -transferente y adquirente-, independientemente de la comunicación al tercero.

Con relación al primer inciso del mencionado artículo $902^{\circ}$, se puede apreciar que su texto tiene una leve pero significativa modificación respecto del que tenía su similar en Código Civil anterior; como se ha indicado el inciso 1) del artículo $845^{\circ}$ del Código Civil de 1936, señalaba: "La tradición se considera realizada cuando: $1^{\circ}$ para quien está poseyendo el bien por título distinto"; por su parte el inciso 1) del artículo $902^{\circ}$ del actual Código Civil Peruano, señala: "la tradición también se considera realizada cuando: $1^{\circ}$ cambia el título posesorio de quien está poseyendo". Si bien la norma anterior entiende realizada la tradición para quien está poseyendo, tal limitación no aparece del nuevo texto normativo, que no precisa respecto de quien se habría producido la entrega, pudiendo entenderse que la mencionada tradición se entiende realizada respecto del que no tiene el bien físicamente, como es el caso del 
constituto posesorio que se presenta cuando el cambio de título posesorio proporciona el derecho de entrega a quien no tiene el bien físicamente; es el caso, por ejemplo, del que vende el inmueble de su propiedad que al mismo tiempo posee, y que no lo entrega físicamente al comprador o nuevo dueño; en tal caso, en virtud de lo previsto en el inciso $1^{\circ}$ del artículo $902^{\circ}$ antes citado, se ha producido la entrega o tradición al adquiriente, quien habría adquirido la posesión de modo espiritualizado, pasando el nuevo dueño a tener la calidad de poseedor mediato, mientras que el anterior dueño pasa a ser el mediador posesorio; por ello, tiene en este caso el adquiriente un derecho de entrega que puede hacerlo valer en la vía restitutoria del desalojo.

\section{POSESIÓN ILEGÍTIM A Y EL TÍTULO POSESORIO}

Nuestra norma sustantiva carece de una regulación que contenga el concepto de la posesión legítima, como sucede en el derecho civil argentino ${ }^{34}$. Sin embargo, tratándose de un tipo de posesión por su origen, es fácil advertir la posesión legítima no es otra -como refiere el profesor Avendaño- que una posesión arreglada a derecho.

Implícitamente nuestro Código Civil identifica en los artículos $900^{\circ}$ y $901^{\circ}$ a la posesión legítima, al señalar que la posesión se adquiere por la tradición -salvo los casos de adquisición originaria- y luego establece que la tradición es la entrega del bien a quien debe recibirlo o a la persona designada por él o por la ley y con las formalidades que ésta establece; sin embargo en esta definición no se prevé un elemento importante, pues nada se dice respecto de la persona que entrega el bien; pues, como es obvio para que la posesión sea legítima, debe ser entregada por la persona autorizada para ello, sea por el propietario o por la ley.

Por su parte la posesión será ilegítima cuando no se encuentre arreglada a derecho. El Código Civil no dice nada sobre este tema y se limita a establecer el supuesto de posesión ilegítima de buena fe, calificándola como aquella en la que el poseedor cree en su legitimidad, por ignorancia o error de hecho o de derecho sobre el vicio que invalida su título; según la citada norma, para que exista posesión ilegítima de buena fe se requiere -necesariamentede la existencia de un título posesorio, y que el poseedor considera válido o legítimo, cuando en realidad no lo es.

No existe en la norma sustantiva definición alguna sobre la posesión ilegítima de mala fe; no obstante se infiere que se trata de la posesión que se ejerce por quien conoce perfectamente de la ilegitimidad o invalidez de su título 
posesorio o que es perfectamente conciente que posee el bien sin título alguno, o con un título manifiestamente inválido o inoponible al que cuenta con derecho inscrito. Dentro de este grupo se ubica precisamente al poseedor precario ${ }_{\iota}$ quien según el artículo $911^{\circ}$ de la norma sustantiva civil, es quien ejerce posesión de un bien sin contar con título posesorio alguno, sea por que nunca lo tuvo o porque el que tenía feneció.

\section{CONCLUSIONES}

1. Con relación a la regulación sobre la posesión, debe incluirse en el texto normativo el siguiente texto sobre la posesión:

a. La posesión es la potestad o señorío fáctico que, con interés propio, ejerce una persona sobre un bien para su aprovechamiento económico y la satisfacción de sus necesidades; aún cuando reconozca en otro la propiedad, el poseedor de un bien es aquel que, en los hechos, se conduce como propietario, usando o disfrutando el bien.

b. La posesión, cualquiera que ésta fuera, no puede ser privada o perturbada al poseedor por acto de particulares; corresponde al órgano jurisdiccional declarar el derecho posesorio a quien corresponda.

c. La posesión será legítima cuando se ejerce con arreglo a derecho, en virtud de un título válido.

d. La posesión será ilegítima cuando se ejerza con título inválido o sin título alguno. Ésta será de buena fe cuando el poseedor, por cualquier causa, cree en la legitimidad de su título. Será de mala fe cuando conozca de la ilegitimidad de su título, carezca de título o éste sea manifiestamente ilegítimo.

e. La posesión precaria es la que se ejerce con título manifiestamente ilegítimo o inválido, o sin título alguno, sea por que nunca lo tuvo o porque el que tenía feneció.

2. En materia de mutación -interversión- del título posesorio debe incluirse en el texto normativo lo siguiente:

a. Se presume, salvo prueba en contrario, que la posesión se mantiene con el mismo carácter con el que fue adquirida.

3. Respecto al título posesorio en la posesión ilegítima, se deben considerar 


\section{en el texto normativo civil las siguientes propuestas: .}

\section{a. La posesión ilegítima de mala fe, que se ejerce en virtud de un título manifiestamente inválido o ineficaz respecto del propietario, equivale a ausencia de título.}

\section{b. Si se adquiere de buena fe la posesión ilegítima, en virtud de un título posesorio, se pierde.}

1 Papaño J, Kiper C, Dillon G y Causse J. Derechos Reales Tomo I.. Buenos Aires: Ediciones Depalma; 1989.

\section{Pág. 59.}

2 Messineo, Francesco. Manual de Derecho Civil y Comercia". Tomo III. Buenos Aires: Ediciones jurídicas Europa-América; 1954. Pág. 203. El mencionado profesor italiano agrega que el ius possidendi está ligado -y la presupone- a la cualidad de titular del respectivo derecho, de ordinario de propiedad.

3 Hernandez, A. La función social de la posesión (Ensayo de teorización sociológico -jurídico). Madrid: El libro de Bolsillo Alianza Editorial; 1969. Pág. 8. El autor refiere, respecto de este punto, con acertado criterio, que la "posesión" no es la propiedad, pero que puede estar o no integrada a ella o a algún otro derecho real; agrega que en éste último supuesto la posesión tiene un significado autónomo.

4 Peña, L. Derecho Civil. Derechos Reales. Buenos Aires: Editora Argentina; 1975. Tomo I. Pág. 187; refiriéndose a la complejidad del tema, este autor argentino señala: "D octrinariamente se considera que es opinión casi unánime que desde la crítica que Ihering hizo a la teoría de la posesión de Savigny se ha enseñoreado en la doctrina la más horrible confusión y el más agudo desconcierto, no existiendo sobre los problemas fundamentales soluciones consagradas ni aún admitidas por una razonable mayoría, ya que puede asegurarse sin incurrir en la exageración que, en materia posesoria, no hay una sola idea que expresa o implícitamente no aparezca negada o desvirtuada, a veces hasta por sus más ardientes defensores."

5 Lama, H. La posesión y la posesión precaria. El nuevo concepto del precario y la utilidad de su actual regulación en el derecho civil peruano. Lima: Editorial Jurídica Grijley EIRL.. 2007. Pág. 201.

6 Enneccerus L, Kipp W. Tratado de Derecho Civil Tercer Tomo D erecho de cosas. Volumen I Barcelona: Bosch, Casa Editorial.. 3ra.ed,1971. Pág. 46 y 47. Refieren los citados autores alemanes que el "servidor de la posesión" no es poseedor, por ello -señalan- no le corresponde las pretensiones posesoria; contra él no se dirige la pretensión de entrega del propietario; agregan que no le es lícito defender por su propia autoridad su relación con la cosa, contra intervenciones del poseedor; no obstante es del caso precisar que los mencionados juristas refieren que lo que distingue al "servidor de la posesión" de los demás noposeedores es el que a él le es lícito ejercer -según refieren, hasta más allá de los límites del derecho general de legítima defensa- los derechos de autoprotección del poseedor contra ataques de extraños; es decir, le es lícito defender la cosa por la fuerza, tal como le sería lícito al poseedor del mismo.

7 Arias-Schreiber, M. Exegesis del Código Civil Peruano de 1984. 2da.ed Lima: Gaceta Jurídica Editores; 1998.Pág. 142.

8 Salvat, R. Derecho Civil argentino (Derechos reales). Tomo I. Buenos Aires: Librería y Casa Editora de Jesús Menéndez; 1927. Pág. 33 y 34.

9 Avendaño, J. Derechos Reales. Materiales de enseñanza para el estudio del Libro V del Código Civil en la Facultad de Derecho. 2da. ed -corregida y aumentada. Lima: Pontificia Universidad Católica del Perú; 1990. Pag. 136 y 137.

10 Messineo, F.. O p. Cit., Pág. 204.

11 Pacheco, T. Tratado de Derecho Civil. 2da.ed. Lima: III. Imprenta de Estado Calle de la Rifa N. $58 ; 1872$. Pág. 71

12 Pescio, V. Manual de derecho Civil. IV. De la colección "Manuales Jurídicos". No 44. Santiago de Chile: Editorial Jurídica de Chile.; 1958. Pág. 181. Este autor, del vecino país de Chile, citando a Pothier señala que "se denomina titulo de posesión todo contrato o acto a consecuencia del cual una persona ha entrado en posesión de una cosa.

13 Expediente signado con el número autogenerado 1998-48554-0-0100-J-CI-20, que puede ser ubicado en el archivo central de la Corte Superior de Justicia de Lima

14 Publicada en el diario Oficial "El peruano" el 30 de junio del 2004, en el Boletín de Sentencias de Casación, 


\section{Héctor Enrique Lama More - El título posesorio en el Derecho Civil Peruano}

Pág. 12177

15 Salvat, R. 0 p cit. Pág 39. Refiere el autor que en ambos casos para que el título putativo equivalga a un título realmente existente, se requiere que el poseedor tenga razones suficientes para creer en la existencia de él o para extender a la totalidad de la cosa poseída. Se debe tratar de un error verdaderamente excusable, lo que será siempre una cuestión de hecho, librada a la apreciación de los jueces en cada caso especial.

16 Salvat, R. Op cit. Pág 39-40.

17 Castañeda, J. Los Derechos Reales. Tomo I. 4ta. ed. Lima: Talleres Gráficos P.L. Villanueva;. 1973. Pág. 367. El profesor Castañeda precisa que son títulos putativos, por ejemplo: Si se concede posesión en base a un testamento que después aparece revocado; cuando erróneamente se señala un lote de urbanización cuando en realidad es otro; cuando se entra en posesión de un bien que no estaba comprendido dentro de la masa hereditaria a la que se tiene derecho a poseer; si el área poseída es mayor que la vendida, no habrá justo título en el exceso, sino título putativo.

18 Castañeda, J. O p cit. Pág. 365

19 Albaladejo, M. "La usucapión". Colegio de Registradores de la Propiedad y mercantiles de España. Centro de Estudios. Imprime: J. San José, S.A. Madrid. 2004. Pág. 84

20 Albaladejo, Ml. Op Cit. Pág. 90

21 Castañeda, J. 0 p cit. Pág. 367.para este autor no son justos títulos el falsificado, pues no fue otorgado por la persona que se dice; tampoco lo es el otorgado por el falso mandatario; no lo es el título radicalmente nulo; tampoco las sentencias judiciales, pues el juez define los derechos, no los transfiere; refiere que no son justo título los títulos supletorios de dominio pues no son traslativos de propiedad.

22 Albaladejo, M. Op Cit. Pág. 92

23 Pescio, V Op Cit. Pág. 519. Este autor reconoce que en su país no existe una regulación que discipline de modo definido y orgánico tan delicada institución. Agrega que los preceptos relativos a la transformación del poseedor en mero detentador apenas si permiten esbozar una doctrina a riesgo de incurrir en una generalización vaga, teorizante y peligrosa; por otro lado, indica que los preceptos concernientes a la transformación del mero detentador en poseedor, constituyen unas cuantas disposiciones legales, desarticuladas entre si , imprecisas y hasta carentes de la coherencia debida..

24 Salvat, R. O p cit. Pág $18-19$

25 Castañeda, J. Op cit. Pág. 115

26 Musto, N. Derechos Reales. Tomo I. Rubinzal y Culzoni SCC Editores. Pág. 213.

27 Artículo $902^{\circ}$ del CC -84: La tradición también se considera realizada:

Cuando cambia el título posesorio de quien está poseyendo.

Cuando se transfiere el bien que está en poder de un tercero. En este caso, la tradición produce efecto en cuanto al tercero solo desde que es comunicada por escrito.

28 Valencia, A. La posesión. Bogotá: Editorial Temis; 1968. Pág. 270-271

29 Artículo $905^{\circ}$ del CC - 84: Es poseedor inmediato el poseedor temporal en virtud de un título. Corresponde la posesión mediata a quien confirió el título.

30 Hernandez, A. La posesióin. Madrid: Editorial Civitas S.A.; 1980. Pág. 134

31 Enneccerus, L. Op Cit. Pág. 55; este autor refiere que en el derecho alemán al que posee sin mediador posesorio se denomina poseedor inmediato

32 Arias-Schreiber, M. Op Cit. Pág. 140.

33 Enneccerus, L. Op Cit. Pág. 58

34 Artículo 2355 del CC argentino: "La posesión será legítima, cuando sea el ejercicio de un derecho real, constituida en conformidad con las disposiciones de éste código. llegítima cuando se tenga sin título, o por un título nulo, o fuere adquirida por un modo insuficiente para adquirir derechos reales, o cuando se adquiera de que tenía derecho a poseer la cosa y no para trasmitirla". Por ley 17711 se agregó el siguiente párrafo: "Se considera legítima la adquisición de la posesión de inmuebles de buena fe, mediante boleto de compra-venta" 